\title{
Mapping nutrient concentration in pasture using hyperspectral imaging
}

\author{
I. YULE ${ }^{1}$, R. PULLANAGARI ${ }^{1}$, M. IRWIN ${ }^{1}$, P. McVEAGH ${ }^{1}$, \\ G. KERESZTURI ${ }^{1} \mathrm{M}$. WHITE ${ }^{2}$ and M. MANNING ${ }^{2}$ \\ ${ }^{I}$ New Zealand Centre for Precision Agriculture, Institute of Agriculture and Environment, Massey University, \\ Palmerston North, New Zealand. \\ ${ }^{2}$ Ravensdown Fertiliser Cooperative, Hornby, Christchurch, New Zealand.
}

i.j.yule@massey.ac.nz

\begin{abstract}
Hyperspectral sensing using ground-based equipment has been demonstrated to be successful in determining pasture nutrient content $(\mathrm{N}, \mathrm{P}, \mathrm{K}, \mathrm{S})$ and parameters such as dry matter content and metabolisable energy. This technology needed to be up-scaled so that large areas could be rapidly covered with adequate spatial resolution. This paper describes work which demonstrates a progression from hyperspectral sensing to hyperspectral imaging which utilises the visible, near infrared and short wave infrared parts of the electromagnetic spectrum. Large scale calibration and validation field trials were conducted at the same time as hyperspectral imaging was completed. These trials demonstrate the feasibility of producing information, in detailed map form, on pasture nutrient concentration and other parameters to inform fertiliser placement decisions as well as other farm management tasks. The technique effectively produces a forage analysis for every square meter of any farm.
\end{abstract}

Keywords: hyperspectral imaging, precision agriculture.

\section{Introduction}

Nutrients are critical for pasture growth and they play an important role in farm productivity and profitability. Typically, nutrient concentration in pasture has been determined in a laboratory where samples cut from the field and dried in an oven were analysed. In contrast, remote sensing, particularly hyperspectral imaging, has been found to be a promising non-destructive tool for estimating nutrient concentrations of vegetation with a very short turn-around time. Along with spatial information, this offers a much more efficient and costeffective way to map pasture nutrient concentration across large areas of land. In hyperspectral imaging, sensors collect electromagnetic radiation originated from the sun, and reflected back from objects in many narrow and contiguous bands (in wavelength) across the electromagnetic spectrum. These sensors can be used from different platforms, such as satellite, airborne and hand-held. Among them, airborne platforms have greater flexibility in collecting data, achieving scale and high resolution. This has the potential to offer high spatial resolution which is essential for accurate quantification of important biochemical properties of vegetation (especially $\mathrm{N}, \mathrm{P}, \mathrm{K}, \mathrm{S}$ ) and bare ground in a heterogeneous environment, e.g. mixed pastures. Pasture reflectance is a function of spectral absorption features caused by biophysical and biochemical properties of vegetation. Models have been developed to estimate nutrient concentrations using hyperspectral data acquired from different sources (Kawamura et al. 2009; Pullanagari et al. 2012; Sanches 2009) with varying degrees of accuracy (Table 1). Of all nutrients, nitrogen $(\mathrm{N})$ has been widely studied because of its vital role in the physiological function of plants. $\mathrm{N}$ absorption features are broad and strong across the electromagnetic spectrum, providing an opportunity to accurately estimate the $\mathrm{N}$ content of vegetation. Conversely, limited focus has been given to estimating other nutrients.

\section{Hyperspectral sensing in hill country}

Following initial success using hyperspectral sensing techniques to describe quality parameters in dairy pasture (Pullanagari et al. 2012), it was decided to complete a similar study focused on hill country pasture at Limestone Downs. This study demonstrated that similar techniques could describe pasture parameters with a high level of accuracy (Table 2). The study also showed the high levels of variability in pasture quality associated in part with the physical geography of the

Table $1 \quad$ Nutrient prediction results using hyperspectral data extracted from various studies; Skidmore et al. (2010), Knox et al. (2011), Ramoelo et al. (2013), Sanches et al. (2013).

\begin{tabular}{ccc}
\hline Nutrient & $\begin{array}{c}\text { Coefficient of } \\
\text { determination (R }\end{array}$ & $\begin{array}{c}\text { Accuracy } \\
\text { (RMSE) }\end{array}$ \\
\hline N & $0.65-0.77$ & $0.35-0.47$ \\
$\mathrm{P}$ & $0.63-0.77$ & $0.05-0.08$ \\
$\mathrm{~K}$ & $0.54-0.76$ & $0.35-0.46$ \\
$\mathrm{~S}$ & 0.49 & 0.90 \\
Dry Matter content (DM) \% & 0.80 & \\
Metabolisable Energy (ME) & 0.83 & 4.13 \\
\hline
\end{tabular}


farm (Table 3). Each of the sampling locations could be clearly identified from the analysis.

Although the study only included 105 laboratory tested samples for calibration, it demonstrated the potential utility of hyperspectral analysis in this farm setting. The main limiting factor was the time and effort required to take a sufficient number of samples to represent the highly variable landscape of typical hill country farm. Although farm managers at Limestone Downs had anticipated that pasture quality may be low in some areas they had underestimated just how low it was.

\section{The potential of high resolution hyperspectral imagery}

Hyperspectral images offer a high level of spatial information that can explain localised distributions of nutrients at farm or regional scale. High resolution maps give a better understanding of how the pasture nutrient concentration is affected by environmental factors and holds promise to optimise the distribution of fertiliser. Ideally, pasture samples taken prior to fertiliser application should represent the spatial heterogeneity arising from multiple sources, including botanical composition, proportion of dead material in the sward and farm management practices. However, the small number of samples collected for nutrient analysis makes it difficult to fully account for spatial variability, which can lead to inaccurate estimates of fertiliser requirements. In order to obtain accurate estimates, very large number of samples would be required which is very expensive process (Cosgrove et al. 1998). High resolution maps created using hyperspectral imaging can be used to estimate the variation of pasture nutrient concentration over the complete area and inform fertiliser application rates and locations. Optimisation of fertiliser placement has the potential to drive productivity and environmental benefits.

\section{Material and methods}

An Aisa FENIX sensor mounted on a Cessna 206 aircraft was used with an RT Oxford Survey+ Global Navigation Satellite System (GNSS) and Inertial Measurement Unit (IMU) system. This sensor is capable of acquiring signals of electromagnetic radiation from $380 \mathrm{~nm}$ (Visible; VIS) to $2500 \mathrm{~nm}$ (Shortwave Infrared; SWIR). It has a spectral sampling interval of 3.4-7.3 $\mathrm{nm}$ from VIS and SWIR region. The aerial surveys were carried out under a condition of (1) solar elevation of $<30^{\circ}$, (2) in the morning (i.e. 10:00 to 13:00) in order to avoid cumulus formation, (3) slowest possible aircraft speed (ca. $105-115$ knots or $194-213 \mathrm{~km} / \mathrm{h}$ ) to maximise exposure time of the ground objects, as well as (4) $\leq 5 \%$ cloud coverage. The flight height ranged between 750 and $850 \mathrm{~m}$ above ground level, which resulted in a Ground Spacing Distance (GSD) of $1 \mathrm{~m}$ and in a swath width of $290 \mathrm{~m}$ to $464 \mathrm{~m}$.

The acquired raw Digital Number (DN) data was converted to radiance values using CaliGeoPRO. A physically based model of atmosphere based on MODTRAN5 was used to process the raw georectified radiance images, using ATCOR 4 (Richter \& Schläpfer 2002). This procedure reduced all unwanted solar

Table 2 Hyperspectral analysis of pasture samples from Limestone Downs 2012.

\begin{tabular}{|c|c|c|c|c|c|c|}
\hline \multirow[t]{2}{*}{ Sample } & \multicolumn{2}{|c|}{$\begin{array}{l}\text { Metabolisable } \\
\text { Energy (ME) }\end{array}$} & \multicolumn{2}{|c|}{$\begin{array}{l}\text { Crude Protein } \\
\text { (CP) }\end{array}$} & \multicolumn{2}{|c|}{$\begin{array}{c}\text { Organic Matter } \\
\text { Digestability (OMD) }\end{array}$} \\
\hline & $\mathbf{R}^{2}$ & RMSE & $\mathbf{R}^{2}$ & RMSE & $\mathbf{R}^{2}$ & RMSE \\
\hline $\begin{array}{l}\text { Dry Sample Spectra, Using ASD Field Spec Pro. } \\
\text { Green Vegetation spectra. In-field }\end{array}$ & 0.95 & 0.20 & 0.96 & 0.75 & 0.95 & 1.44 \\
\hline Using ASD Field Spec Pro. & 0.83 & 0.34 & 0.80 & 1.66 & 0.85 & 2.63 \\
\hline Green Vegetation spectra. In-field & & & & & & \\
\hline Using ASD Handheld 2 & 0.74 & 0.46 & 0.69 & 2.09 & 0.76 & 3.27 \\
\hline
\end{tabular}

Table 3 Wet chemistry analysis of pasture samples taken from site 1 and 6 from Limestone Downs 2012.

\begin{tabular}{|c|c|c|c|c|c|c|}
\hline \multirow[t]{2}{*}{ Sample } & \multicolumn{2}{|c|}{$\begin{array}{l}\text { Metabolisable Energy ME } \\
\text { (MJ/kg) }\end{array}$} & \multicolumn{2}{|c|}{$\begin{array}{l}\text { Crude Protein } \\
\text { CP } \%\end{array}$} & \multicolumn{2}{|c|}{$\begin{array}{c}\text { Organic Matter } \\
\text { Digestibility OMD \% }\end{array}$} \\
\hline & Average & Range & Average & Range & Average & Range \\
\hline Site 1 & 10.30 & $10-11$ & 20 & $18-22$ & 68 & $65-73$ \\
\hline Site 6 & 7.65 & $7.2-8.2$ & 8.5 & $7.8-12$ & 47 & $45-52$ \\
\hline
\end{tabular}


illumination and atmospheric effects, such as aerosol scattering and water vapour absorption from the imagery, ensuring the direct comparison with other atmospherically corrected spectra. The image strips were then mosaicked together, and smoothed spatially with a $3 \times 3$ median filter.

Spectra from the image in the corresponding sampling areas were extracted for building a calibration model. A series of pre-processing tools were applied on the raw spectra to enhance the spectral properties and reduce the noise fraction. After this, multivariate statistics, partial least squares (PLSR) was applied to regress against the real values of the spectra. The developed calibration model was applied to the spectral image obtained from Aisa FENIX.

Pasture $\mathrm{P}, \mathrm{K}$, and $\mathrm{S}$ concentrations were measured using an Inductively Coupled Plasma Mass Spectrometer (ICP-MS). Nitrogen was measured using a CNS Gas Analyser.

\section{Results and Discussion}

Hyperspectral remote sensing has been shown to be capable of producing accurate estimates of forage nutrient concentration through calibration with the results from dried and laboratory prepared samples. It can also be used on fresh samples in the field, eliminating the need for expensive and time-consuming pre-processing although there is some loss of accuracy (see Table 1). The Aisa FENIX imaging system has a similar spectral range to the sensors used in laboratory analysis. The VIS/NIR and SWIR range is required and the imaging system has a sufficient number of discrete wavebands (448) to be capable of estimating nutrient concentrations in mixed pasture on hill country.

Detailed maps of nutrients and other parameters of interest (N, P, K, S, dry matter content and metabolisable energy) can be rapidly produced. The hyperspectral calibration and validation work conducted in this programme has formed the largest data set of hill country pasture ever taken in New Zealand, with over

Table 4 Calibration model statistics for pasture nutrients $(\mathrm{N}, \mathrm{P}, \mathrm{K}, \mathrm{S})$, dry matter content (\%DM) and metabolisable energy (ME) of mixed pasture using PLSR.

\begin{tabular}{lll}
\hline & $\mathbf{R}^{2}$ & RMSE \\
\hline Nitrogen & 0.83 & 0.40 \\
Phosphorus & 0.80 & 0.029 \\
Potassium & 0.90 & 0.32 \\
Sulphur & 0.88 & 0.036 \\
\%DM & 0.78 & 4.91 \\
ME & 0.79 & 0.81 \\
\hline
\end{tabular}

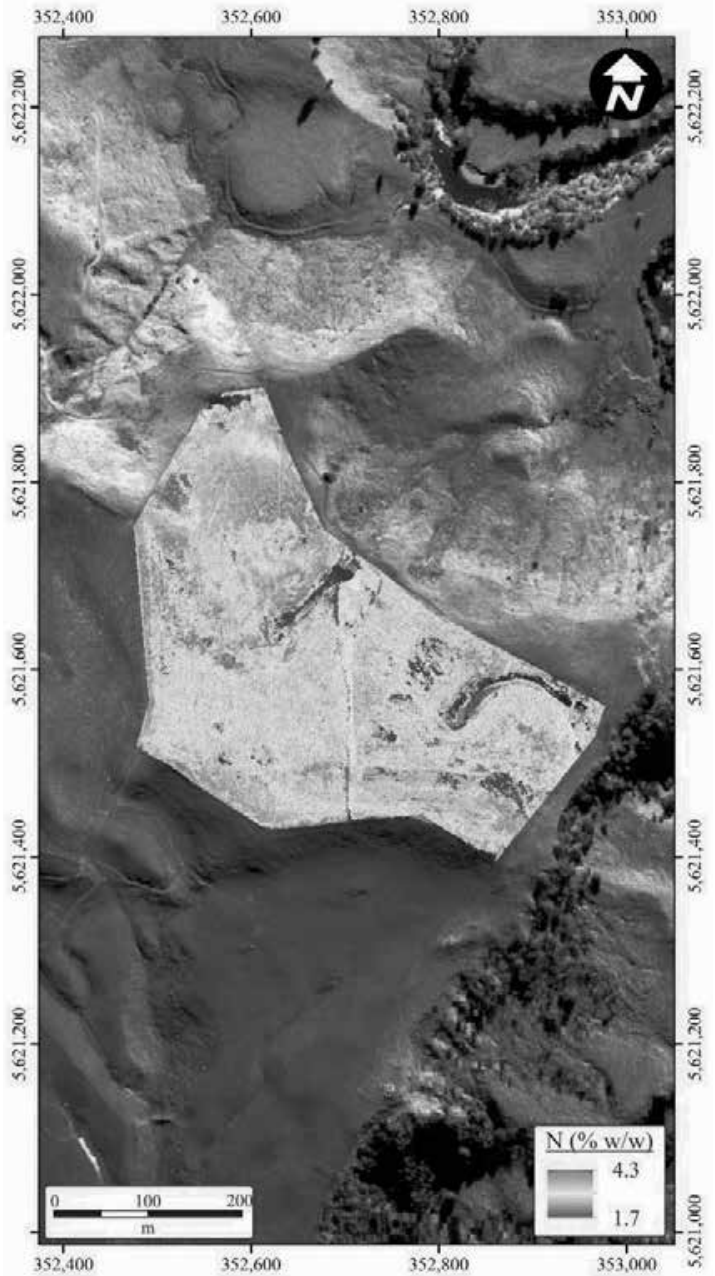

Figure 1 Nitrogen spatial map of a paddock produced using hyperspectral image. Ohorea, Atihau Whanganui Incorporation

4000 laboratory analysed pasture samples used to date. The calibration correlations of observed with measured data are high (Table 4, cf. Table 1) and provide confidence in the use of hyperspectral imagery to inform farm management decisions.

Nutrients can be mapped with a level of detail that allows optimised nutrient and grazing management for any area of the farm (Figure 1). Conventional sampling for $\mathrm{N}$ concentration gave one average value $(2.2 \%)$ for the paddock. The hyperspectral maps provided a much more complete understanding of the spatial variability in $\mathrm{N}$ concentration within this paddock: an average value of $3.1 \%$ with a range from $1.7 \%$ to $4.3 \%$. This information can be used to inform fertiliser application rates and placement, improving the farm financial and environmental performance. 
Hyperspectral imaging is a very flexible technology that can offer a number of advantages over conventional techniques, which are too costly, slow and time consuming. All of the information required to estimate each parameter is collected in one operation once that parameter has been calibrated and validated. Information that can be used to inform fertiliser application is collected at the same time as information useful to the farmer to inform optimised grazing strategies as well as identifying areas most suitable for re-development, intensification or partial retirement. Previous techniques are fraught with problems and potential sources of error as well as being time consuming and expensive. They do not present an economically viable method of providing information necessary for improving farm management and fertiliser plans to individual farmers.

This is the first time that farmers have had a viable high resolution map of pasture nutrient concentration that can inform their farming decisions. Initial feedback from farmers has been extremely positive and they have expressed a great deal of interest in using the information produced from this technology on their own property. Farmers have been keen to ask a range of questions around productivity and potential as well as understand how their fertiliser programme can be optimised. Many have found the range of results surprising, paying increased attention to areas of low quality.

Further validation work is yet to be completed but the data set used is already considerably larger than anything previously produced in New Zealand. Further farms in different geographic regions of New Zealand are also being tested to check and validate the robustness of the algorithms used to describe pasture nutrient concentration and other parameters of interest.

\section{ACKNOWLEDGEMENTS}

The authors would like to acknowledge the C. Alma Baker Trust for jointly funding an initial trial with Massey University, NZCPA in 2012. The authors would also like to acknowledge the management of Limestone Downs for their help and cooperation.

The work on hyperspectral imaging described in this paper was completed as part of the Ravensdown/ Ministry of Primary Industry, (Primary Growth Partnership, PGP) sponsored project, Pioneering to Precision: Application of Fertiliser in Hill Country.

The efforts of the teams from Massey University and AgResearch carrying out the field work on the PGP project are acknowledged as well as the cooperating farmers. All samples were processed through Analytical Research Laboratories of Ravensdown in Napier.

\section{REFERENCES}

Cosgrove, G.P.; Betteridge, K.; Thomas, V.J.; Corson, D.C. 1998. A sampling strategy for estimating dairypasture quality. Proceedings of the New Zealand Society of Animal Production 58: 29-31.

Kawamura, K.; Betteridge, K.; Sanches, I.D.; Tuohy, M.P.; Costall, D.; Inoue, Y. 2009. Field radiometer with canopy pasture probe as a potential tool to estimate and map pasture biomass and mineral components: a case study in the Lake Taupo catchment, New Zealand. New Zealand Journal of Agricultural Research 52: 417-434.

Knox, N.M.; Skidmore, A.K.; Prins, H.H.T.; Asner, G.P.; van der Werff, H.M.A.; de Boer, W.F.; van der Waal, C.; de Knegt, H.J.; Kohi, E.M.; Slotow, R.; Grant, R.C. 2011. Dry season mapping of savanna forage quality, using the hyperspectral Carnegie Airborne Observatory sensor. Remote Sensing of Environment 115: 1478-1488.

Pullanagari, R.; Yule, I.; Tuohy, M.; Hedley, M.; Dynes, R.; King, W. 2012. In-field hyperspectral proximal sensing for estimating quality parameters of mixed pasture. Precision Agriculture 13: 351-369.

Ramoelo, A.; Skidmore, A.K.; Cho, M.A.; Mathieu, R.; Heitkönig, I.M.A.; Dudeni-Tlhone, N.; Schlerf, M.; Prins, H.H.T. 2013. Non-linear partial least square regression increases the estimation accuracy of grass nitrogen and phosphorus using in situ hyperspectral and environmental data. ISPRS Journal of Photogrammetry and Remote Sensing 82: 27-40.

Richter, R.; Schläpfer，D. 2002. Geo-atmospheric processing of airborne imaging spectrometry data. Part 2: Atmospheric/topographic correction. International Journal of Remote Sensing 23: 26312649.

Sanches, I.D. 2009. Hyperspectral proximal sensing of the botanical composition and nutrient content of New Zealand pastures. (Unpublished PhD thesis), Massey University, Palmerston North, New Zealand. Sanches, I.D.; Tuohy, M.P.; Hedley, M.J.; Mackay, A.D. 2013. Seasonal prediction of in situ pasture macronutrients in New Zealand pastoral systems using hyperspectral data. International Journal of Remote Sensing 34: 276-302.

Skidmore, A.K.; Ferwerda, J.G.; Mutanga, O.; Van Wieren, S.E.; Peel, M.; Grant, R.C.; Prins, H.H.T.; Balcik, F.B.; Venus, V. 2010. Forage quality of savannas - Simultaneously mapping foliar protein and polyphenols for trees and grass using hyperspectral imagery. Remote Sensing of Environment 114: 64-72. 